\title{
EDITORIAL \\ The Journal of Perinatology: looking forward
}

(c) The Author(s), under exclusive licence to Springer Nature America, Inc. 2021

Journal of Perinatology (2021) 41:2700-2701; https://doi.org/ 10.1038/s41372-021-01291-4

The Journal of Perinatology is celebrating its fortieth anniversary this year. Remarkably, only three people have served as Editor-inChief of the Journal, Gil Martin, Ned Lawson, and me. In this issue, Gil and Ned discuss their experiences running the Journal. Their stories are humbling and inspiring. Receiving manuscripts, performing reviews, corresponding with authors and production staff all via mail is, retrospectively, nothing short of remarkable. Things have come a long way. Manuscript submission, referee solicitation, manuscript review, and production are all electronic. From two print editions a year, the Journal now appears in both print and electronic editions on a monthly basis.

What are emerging trends and tools in biomedical research publishing that will likely influence the Journal of Perinatology? Some of these include the creation of digital content and its consumption by readers via the use of mobile technology, utilization of preprint servers and their impact on scientific review and public perception, and the growing use of artificial intelligence (Al) in the publication process.

The creation of digital content has led to the rapid sharing of biomedical and scientific information via numerous platforms. Libraries with stacks of books are being replaced by digital archives where readers can rapidly access the content of all types including journals and textbooks. Journal articles are more and more frequently being accompanied by a graphical or visual abstract, explaining, and encapsulating the work in a single pictorial summary, allowing readers to quickly grasp the primary findings of the study. Graphical abstracts encourage rapid browsing, allow readers to quickly identify studies of interest, are claimed to promote interdisciplinary scholarship, and lead to increased visibility on social media. Finally, more and more biomedical content is being consumed via portable devices, not traditional paper journals or textbooks. The convenience of this is unheralded. One can access information about a specific medical issue while standing at the patient's bedside. This shift has led to creative strategies to share digital content across a variety of platforms including smartphones, handheld tablets, portable computers, even smartwatches. Information is served to readers in various sized bites (no pun intended). A parallel development has been increased author education for utilization of drawing and other related programs to create digital content for their studies.

Preprint servers are online repositories of manuscripts and data sets that have not yet been accepted by or published in a biomedical journal. While these preprints often undergo basic screening, e.g., plagiarism checks, no peer review has been performed, and articles are rapidly posted online. Preprint servers are hosted by a variety of sources including scientific or academic societies, publishers, academic institutions, funding organizations. Preprint servers index their content on various servers such as Google Scholar, Prepubmed, Europe PMC, and SciLi. Once online, preprints are citable. Most preprint servers maintain the content online permanently. Some allow comments from readers to be posted along with the manuscript. Preprint servers have been developed in response to researchers' concerns that traditional peer review is a lengthy process that delays the dissemination of important research results. Some use them to stake a claim of first by placing preprint articles online. Others enjoy the back-andforth comments, utilizing them to improve a manuscript before submission to a traditional peer-reviewed journal. During the COVID-19 pandemic, press outlets frequently reported results from nonpeer-reviewed manuscripts posted online.

The pros and cons of preprint servers continue to be debated. Should preprint server manuscripts be cited or citable in peerreviewed manuscripts? Should authors submitting manuscripts to peer review journals be expected to cite preprint manuscripts? If so, how can authors manage this with the proliferation of preprint servers? Do preprint manuscripts establish a "first" to publish claim? What if there is plagiarism and data to be retracted and the manuscript should not be published, who is accountable? If an article is posted on a preprint server, are the authors expected to share data and reagents described in the manuscript? Stepping back, most everyone agrees that rapid dissemination of data is important to accelerate both patient care and biomedical research. Is the problem with preprint servers, whose goal is to rapidly disseminate scientific data, or is it with peer review? How can journals work to improve and quicken peer review and decrease time to publication? These are important issues for the biomedical publishing community.

The use of Al, defined in broad terms as computers performing tasks mimicking human behavior utilizing large amounts of relevant data, has been driven by advances in algorithms, the generation of large digital databases, and improvements in computing. $\mathrm{Al}$ is being employed in everything from industry, finance, and medicine to farming, gaming, and the military. In biomedical publishing, Al holds great promise in several aspects, resulting in the faster publication of high-quality manuscripts. Roles include extracting data from manuscripts after submission to obviate authors completing tedious form filling, analyzing manuscripts for plagiarism, verifying citations, and analyzing figures for potential image manipulation. The Journal of Perinatology utilizes the iThenticate algorithm as a plagiarism checking tool.

In peer review, Al can be utilized to assist editors and reviewers identify previously published relevant work that might have been missed by the authors and/or the editors/reviewers. It can be employed to identify potential reviewers. It can perform various aspects of review such as examination of methodologies, statistical analyses, etc. to aid reviewers and editors. It can be utilized in various aspects of post-acceptance manuscript production. Al can be used to help publishers aggregate similar content, facilitate readers in identifying work of interest, and assist investigators in accelerating their research. Recent examples include the various databases created to accelerate COVID-19 research via modeling, disease symptomatology, etc. 
Going forward, the Journal has several objectives. Continuing to attract high-quality content in the form of original research, reviews, and commentary remains a high priority. Outreach to broaden both readership and the Editorial Board in terms of gender, race, and geography is another important objective. Collaboration with our associated societies, the Section on Neonatal Perinatal Medicine (SoNPM) of the American Academy of Pediatrics (AAP) and the National Perinatal Association, is an important activity of the Journal. Developing collaborations with other relevant groups and societies has started and is a process we continue to pursue. Recently, a number of article clusters have been published including Disparities in Perinatal Medicine, COVID19, Patent Ductus Arteriosus (all three published), Essentials of Neonatal Perinatal Medicine Fellowship in collaboration with the Organization of Neonatal-Perinatal Medicine Training and an article cluster with AAP SoNPM Advocacy Group (both coming 2022). Others are in the works. In the Editorial Office, utilizing datadriven approaches to monitor trends is leading to novel approaches to improve various editorial and production aspects of the Journal.

The Journal of Perinatology will continue to grow from its strengths. Journal authors and readership represent a broad base of perinatologists, neonatologists, allied health personnel, and trainees. There are strong ties with the AAP SoNPM and NPA. The Journal has an experienced editorial board and a well-respected, innovative publisher, Springer Nature. Journal submissions are increasing, and review times are decreasing. Publishing metrics including 2- and 5-year impact factors, JCR rank, and Immediacy Score are increasing.

We continue to assess the needs of our authors and subscribers and review whether the Editorial team is addressing these needs. Is content topical? Is research high impact? Are reviews fair and timely? How can we make the experience easier for authors and reviewers? We strive to serve the needs of the AAP and SoNPM,
NPA, and other collaborative groups and in turn increase Journal readership, relevance, and reputation.

We owe a lot to Gil Martin and Ned Lawson for their 40 years of contributions to the Journal of Perinatology. Their editorials indicate that their work was a true labor of love. The ultimate goal of the Journal of Perinatology reflects what Gil, Ned, and all of us work every day to achieve: improve the lives of mothers, babies, their families.

Patrick G. Gallagher (iD ${ }^{1,2 \bowtie}$

${ }^{1}$ Departments of Pediatrics, Pathology, and Genetics, Yale University, New Haven, CT, USA. ${ }^{2}$ Yale New Haven Children's Hospital, New Haven, CT, USA. ${ }^{\bowtie}$ email: patrick.gallagher@yale.edu

\section{AUTHOR CONTRIBUTIONS}

PGG conceptualized and wrote the editorial.

\section{COMPETING INTERESTS}

PGG is Editor-in-Chief for the Journal of Perinatology. He has no other conflicts of interest, financial or otherwise, relevant to this article to disclose.

\section{ADDITIONAL INFORMATION}

Correspondence and requests for materials should be addressed to Patrick G. Gallagher.

Reprints and permission information is available at http://www.nature.com/ reprints

Publisher's note Springer Nature remains neutral with regard to jurisdictional claims in published maps and institutional affiliations. 